\title{
Log Linear Models for Religious and Social Factors affecting the practice of Family Planning Methods in Lahore, Pakistan
}

\author{
Farooq Ahmad \\ Department of Statistics \\ Govt. College Pattoki, Pakistan \\ Sohail Chand \\ Institute of Statistics \\ University of the Punjab \\ Q. A. Campus, Lahore, Pakistan
}

\begin{abstract}
This is cross sectional study based on 304 households (couples) with wives age less than 48 years, chosen from urban locality (city Lahore). Fourteen religious, demographic and socioeconomic factors of categorical nature like husband education, wife education, husband's monthly income, occupation of husband, household size, husband-wife discussion, number of living children, desire for more children, duration of marriage, present age of wife, age of wife at marriage, offering of prayers, political view, and religiously decisions were taken to understand acceptance of family planning. Multivariate log-linear analysis was applied to identify association pattern and interrelationship among factors. The logit model was applied to explore the relationship between predictor factors and dependent factor, and to explore which are the factors upon which acceptance of family planning is highly depending. Log-linear analysis demonstrate that preference of contraceptive use was found to be consistently associated with factors Husband-Wife discussion, Desire for more children, No. of children, Political view and Duration of married life. While Husband's monthly income, Occupation of husband, Age of wife at marriage and Offering of prayers resulted in no statistical explanation of adoption of family planning methods.
\end{abstract}

Keywords: Log-Linear Models, Odds ratio, Logit Models.

\section{Introduction}

Pakistan has been experiencing rapid population growth since second half of century due to the reduction mortality and persistent high birth rate. The country's population grew from nearly 33 million in 1947 to about 135 million to date. (Mahmood and Ali 1997). Rapid growth in population has ranked Pakistan eleventh in the world and third biggest contributor to the world population growth. To check the growth rate, it is necessary to understand the process through which the fertility behavior is regulated in a given cultural set up.

There is great deal of effects of religion upon society in Pakistan. The acceptance of family planning in Pakistan is determined by various factors and may vary between difference regiments of population according to various socioeconomic, cultural and economic factors and is generally associated with various aspects of economic, religious and social organization. 
Sabihuddin and Jamal (1993) built the equation which relates the women's total births over the productive career as a function of prominate and deliberate fertility control variable on cross-sectional data. Finally, explanatory variables used in previous stages equated as dependent variable with the set of socio-economic and cultural variables, which are traditionally thought to the factors affecting fertility behavior. The impact of socio-economic modernisation on fertility has been discussed. Socio-economic and cultural variables explained about 0.3 to 7 percent of the variation in the dependent variables.

Zafar (1996) attempted to find the extent to which socio-economic, cultural variables and additionally attitudinal variables such as husband and wife education, family income, husband's occupation, child mortality, exposure to mass media, husband authority and domination in family influence the decision making process for the family planning methods. The Chi-square test was employed to explore the relationship between the predictor variables and dependent variable. Multiple linear regression was also used to establish the relative importance of each the predictor variables.

Hakim (1995) examined that use of family planning methods in Pakistan is determined by various factors and may vary between difference segments if population according to various socio-economic, cultural and economic factors. The author used logit models to determine the effect of the desire for no more children on the current use of family planning methods. To see the independent effect of the desire of no more children on the contraceptive use, the variables like number of living children, women's education and women's work status were controlled one by one. The odd ratios indicated that chances of current use of contraceptives are about seven times higher among women who desire no more children then among those who desire more.

Farooqi, (1994) examined the importance of husband wife communication in the adoption of family planning methods. A series of basic cross tabulation were run separately for 6393 currently married women from the Pakistan demographic and health survey data. After simple bivariate analysis, logistic regression analysis was used by the researcher.

Ali, and White (2005) conducted a cross-sectional community-based survey from May to June 2000 in Khairpur District, Sindh. To determine the prevalence and sociodemographic factors associated with family planning practices among currently married women in Khairpur District, Sindh, Pakistan. A pre-tested structured questionnaire was used to interview 300 subjects from the study area. Stratified cluster sampling was done to collect information on knowledge and use of family planning methods and other sociodemographic factors from the 
respondents. In this series $62 \%$ of the women were illiterate. Nearly $45 \%$ of the women were in the age group of $25-34$ years. Exposure to family planning messages was greater by television $(66 \%)$ than by radio $(55 \%)$. The prevalence of family planning methods among married women was $27 \%$. Oral contraceptive pills were the predominant method used (32\%). Regarding sociodemographic factors, more than four living children, exposure to family planning messages on TV, and husband's approval were the main factors associated with the use of family planning methods.

\section{Materials and Methods}

The study was based on three sets of variables (i) socio-economic and demographic conditions indicated by the back-ground variables (ii) religious variables (iii) dependent variable, acceptance of family planning methods. A married couple in the reproductive age group was taken as a unit of study. Bivariate chi-square test was used to test the association between various factors and dependent variable under study. The sampled population was married couples of Lahore city. Due to unavailability of appropriate sampling frame, multistage sampling was used and data were collected on 304 husbands from Allama lqbal town on the fourteen factors as Husband's education (HE), Wife's education (WE), Husband's monthly income (M), Husband's Occupation $(\mathrm{O})$, Household size $(\mathrm{H})$, Husband-Wife discussion on family planning issues $(\mathrm{HW})$, Number of living children (N), Desire for more children (D), Duration of marriage (DU), Present age of wife (P), Age of wife at marriage (A), Offering of prayers for husband (OP), Political view of husband (PV), Religiously decisions by husband (RD) and acceptance of family planning methods (FP).

Let the data comprise a set of counts $Y^{\top}=\left(Y_{1}, \ldots, Y_{k}\right)$ each component independently Poisson distributed whose respective means are $\mu_{1}, \ldots, \mu_{\mathrm{k}}$. A loglinear model is defined by a set of relations

$$
\eta_{\mathrm{i}}(\beta)=\log \left(\mu_{\mathrm{i}}\right)=\mathrm{x}_{\mathrm{i} 1} \beta_{1}+\mathrm{x}_{\mathrm{i} 2} \beta_{2}+\ldots+\mathrm{x}_{\mathrm{ip}} \beta_{\mathrm{p}} ; \quad \mathrm{i}=1, \ldots, \mathrm{k}
$$

Where $\beta_{1}, \ldots, \beta_{\mathrm{p}}$ are unknown parameters and for each $\mathrm{Y}_{\mathrm{i}}$ the covariates $x_{i}^{\top}=\left(x_{i 1}, \ldots, x_{i p}\right)$ have been measured. This is the systematic component of the model, the random component being the assumed Poisson distribution. The $(k \times p)$ matrix $X$ is called the design matrix.

\section{Results and Discussion}

The association of every socio-economic, demographic and religious factors was tested with the acceptance of family planning with the Chi-square test. (Agresti 1996) The results are shown in Table-1 
Farooq Ahmad, Sohail Chand

Table 1:

\begin{tabular}{|c|c|c|c|}
\hline Variables & Chi-square Value & d.f. & p-value \\
\hline OP & 1.838 & 1 & 0.175 \\
\hline PV & 11.589 & 1 & $0.001^{*}$ \\
\hline RD & 1.840 & 1 & 0175 \\
\hline N & 24.821 & 2 & $0.000^{*}$ \\
\hline D & 53.706 & 1 & $0.000^{*}$ \\
\hline DU & 6.304 & 2 & $0.043^{*}$ \\
\hline A & 4.791 & 2 & 0.091 \\
\hline P & 6.05 & 2 & 0.218 \\
\hline HE & 2.210 & 1 & 0.137 \\
\hline WE & 1.187 & 1 & 0.179 \\
\hline O & 2.124 & 1 & 0.145 \\
\hline M & 3.766 & 1 & 0.052 \\
\hline H & 0.969 & 2 & 0.616 \\
\hline HW & 47.418 & 1 & $0.000^{*}$ \\
\hline
\end{tabular}

PV, N, D and HW were found to be the highly significant factor and DU was found to be significant factor. All other factors were found to be non-significant. In order to model the association pattern and to study the affect of all factors upon the decision making process of the acceptance of family planning methods, multivariate log-linear analysis have been applied. To over come the difficulty of over-dimensionality of the contingency table with fifteen variables, all the factors of explanatory nature were divided into four marginal groups by keeping the dependent variable in each group. This step helped to simplify the interpretation of the results by avoiding the higher order interaction terms which are impractical (Afifi and Clark(1994)). All the factors were distributed arbitrarily among four marginal groups by keeping the factor under study. These groups were rearranged to avoid the higher order interaction terms. Finally these marginal groups have been constructed.

Group1: FP, A, HW, HE, RD

Group 2: FP, N, O, M, OP

Group 3: FP, D, DU, WE

Group 4: FP, P, H, PV

\section{Group 1:}

In order to search the good fitted model on FP, A, HW, HE and RD, simultaneous tests that the k-factor interaction terms are zero, has been applied. Simultaneous test indicated that 5-factor, all four-factor and all 3-factor interaction terms are insignificant. So keeping all possible 2-factor interaction terms, Backward elimination procedure has been applied for the purpose of best fitted model 
selection. The best model has generating class (FE, FP* $\mathrm{HW}, \mathrm{HE}^{*} \mathrm{HW}, \mathrm{A}^{*} \mathrm{HE}$ ) with $\mathrm{G}^{2}=29.284$ d.f. $=37, \mathrm{p}=0.83$.

The structural form of model is

Table 2:

\begin{tabular}{|l|c|c|c|c|c|}
\hline \multirow{2}{*}{ Parameters } & \multirow{2}{*}{ Estimate } & \multirow{2}{*}{ SE } & \multirow{2}{*}{ Z-value } & \multicolumn{2}{|c|}{$\begin{array}{c}\text { Asymptotic 95\% } \\
\text { Confidence Interval }\end{array}$} \\
\cline { 5 - 6 } & & & & Lower & upper \\
\hline Constant & 1.4122 & - & - & - & - \\
\hline $\mathrm{A}(1)$ & 0.3659 & 1.984 & 1.84 & -0.2 & 0.75 \\
\hline $\mathrm{A}(2)$ & 0.9837 & 0.1787 & 5.50 & 0.63 & 1.33 \\
\hline $\mathrm{FP}(1)$ & -1.3291 & 0.2164 & -6.14 & -1.75 & -0.90 \\
\hline $\mathrm{HE}(1)$ & -0.9719 & 0.3530 & -2.75 & -1.66 & -0.28 \\
\hline $\mathrm{HW}(1)$ & -0.2332 & 0.1732 & -1.35 & -0.57 & 0.11 \\
\hline $\mathrm{RD}(1)$ & 0.7885 & 0.1237 & 6.37 & 0.55 & 1.03 \\
\hline $\mathrm{A}(1)^{\star} \mathrm{HE}(1)$ & 1.1004 & 0.3768 & 2.92 & 0.36 & 1.84 \\
\hline $\mathrm{A}(2)^{\star} \mathrm{HE}(1)$ & -0.4729 & 0.4066 & -1.16 & -1.27 & 0.32 \\
\hline $\mathrm{FP}(1)^{\star} \mathrm{HW}(1)$ & 1.7585 & 0.2660 & 6.61 & 1.24 & 2.28 \\
\hline $\mathrm{HE}(1)^{\star} \mathrm{HW}(1)$ & -0.5579 & 0.2587 & -2.16 & -1.06 & -0.05 \\
\hline
\end{tabular}

Estimated log odds-ratio to the corresponding parameters are given in the Table2. Remaining parameter are redundant parameters and set to zero. The estimate of parameter $\mathrm{A}(1)^{*} \mathrm{HE}(1)$ in the table-2 is 1.004 and $e^{1.004}=2.73$ and hence conditional odd ratio is 2.73 i.e. chance for marriage of women in younger age is 2.73 times more of those husbands whose education is secondary or less, by keeping other factors constant. Conditional odd ratio for parameter $\mathrm{FP}(1)^{\star} \mathrm{HW}(1)$ became $e^{1.7585}=5.80$ and hence the fitted model that odds of acceptance of family planning methods is 5.80 times the odds of husbands who have discussed with there wives on the number of children. More generally, there are 5.80 times more chances to accept the family planning for those husbands who have discussed with their wives on the mater of number of children. Table-2 also indicated that there is negative association between low education and husband wife discussion, at each combination of levels of A, FP and RD.

\section{Group 2:}

Five factors (FP, M, N, O, OP) were included in group 2 and five way contingency table $(3 \times 2 \times 2 \times 2 \times 2)$ had been constructed. In order to search good fitted model, all possible 2 -factor interaction terms were included in the model and backward elimination procedure produced the final model with generating class (OP, $\left.\mathrm{FP}^{\star} \mathrm{N}, \mathrm{M}^{\star} \mathrm{O}\right)$. 
Farooq Ahmad, Sohail Chand

The likelihood ratio Chi-square is $G^{2}=48.70$ d.f. $=38 \quad p=0.114$

Table 3:

\begin{tabular}{|l|c|c|c|c|c|}
\hline \multirow{2}{*}{ Parameter } & \multirow{2}{*}{ Estimate } & \multirow{2}{*}{ S E } & \multirow{2}{*}{ Z-value } & \multicolumn{2}{|c|}{$\begin{array}{c}\text { Asymptotic 95\% } \\
\text { Confidence Interval }\end{array}$} \\
\cline { 5 - 6 } & & & & Lower & Upper \\
\hline Constant & 2.0253 & - & - & - & - \\
\hline $\mathrm{FP}(1)$ & -0.3983 & 0.1886 & -2.11 & -0.77 & -0.03 \\
\hline $\mathrm{M}(1)$ & 0.0774 & 0.1488 & 0.52 & -0.21 & 0.37 \\
\hline $\mathrm{N}(1)$ & $-2.43 \mathrm{E}-14$ & 0.1690 & $-1.43 \mathrm{E}-13$ & -0.33 & 0.33 \\
\hline $\mathrm{N}(2)$ & -0.8145 & 0.2157 & -3.78 & -1.24 & -0.39 \\
\hline $\mathrm{O}(1)$ & -0.0116 & 0.1521 & -0.08 & -0.31 & 0.29 \\
\hline $\mathrm{OP}(1)$ & 0.4968 & 0.1183 & 4.20 & 0.27 & 0.73 \\
\hline $\mathrm{FP}(1)^{*} \mathrm{~N}(1)$ & -0.4829 & 0.2904 & -1.66 & -1.05 & 0.09 \\
\hline $\mathrm{FP}(1)^{*} \mathrm{~N}(2)$ & 1.0074 & 0.2922 & 3.45 & 0.43 & 1.58 \\
\hline $\mathrm{M}(1)^{\star} \mathrm{O}(1)$ & -0.9208 & 0.2466 & -3.73 & -1.40 & -0.44 \\
\hline
\end{tabular}

Table-3 indicated that conditional $\mathrm{FP}(1)^{\star} \mathrm{N}(1)$ odds-ratio is $\mathrm{e}^{-0.4829}=0.62$ i.e. those families who have no or one child provides $38 \%$ protection to adopt the contraceptives, as compare to those who have four or more children. Table-3 also indicted that low income of husband is $40 \%$ less likely to occur for husbands who are businessmen, at each combination of levels of FP, N and OP.

\section{Group 3:}

Four factors FP, D, DU and WE were included in the marginal group 3. 4-way contingency table was constructed with 24 cells. In order to search good fitted model simultaneous test that k-factor interaction terms are zero have been applied. The final model produced by backward elimination procedure gave generating class $\left(D^{\star} D U, D^{*} F P, D U^{\star} F P, D U^{\star} W E\right)$. The likelihood ratio Chi-square test for the fitted model has

$G^{2}=11.506$ d.f. $=11 \quad p=0.402$. The structural form of the log linear model is given below,

As the absence of two 2-factor interaction terms which are $D^{*} W E$ and $F P^{*} W E$ implies the conditional independence for $D$ and WE at each combination of levels of DU and FP. Parameter estimates were given for group 3 in table-4. 
Table 4:

\begin{tabular}{|l|c|c|c|c|c|}
\hline \multirow{2}{*}{ Parameters } & \multirow{2}{*}{ Estimate } & \multirow{2}{*}{ S E } & \multirow{2}{*}{ Z-value } & \multicolumn{2}{c|}{$\begin{array}{c}\text { Asymptotic 95\% } \\
\text { Confidence Interval }\end{array}$} \\
\cline { 5 - 6 } & & & & Lower & Upper \\
\hline Constant & 2.2528 & - & - & - & - \\
\hline $\mathrm{D}(1)$ & 0.2977 & 0.2265 & 1.31 & -0.15 & 0.74 \\
\hline $\mathrm{DU}(1)$ & -2.2434 & 0.5062 & -4.43 & -3.24 & -1.25 \\
\hline $\mathrm{DU}(2)$ & -1.7874 & 0.4937 & -3.62 & -2.75 & -0.82 \\
\hline $\mathrm{FP}(1)$ & 0.2245 & 0.2299 & 0.98 & -0.23 & 0.68 \\
\hline $\mathrm{WE}(1)$ & 0.8391 & 0.2023 & 4.15 & 0.44 & 1.24 \\
\hline $\mathrm{D}(1)^{\star} \mathrm{DU}(1)$ & 304332 & 0.4808 & 7.14 & 2.49 & 4.38 \\
\hline $\mathrm{D}(1)^{\star} \mathrm{DU}(2)$ & 1.9089 & 0.4693 & 4.07 & 0.99 & 2.83 \\
\hline $\mathrm{D}(1)^{\star} \mathrm{FP}(1)$ & -3.0439 & 0.4298 & -7.08 & -3.89 & -2.20 \\
\hline $\mathrm{DU}(1)^{\star} \mathrm{FP}(1)$ & 2.2235 & 0.4634 & 4.80 & 1.32 & 3.13 \\
\hline $\mathrm{DU}(2)^{\star} \mathrm{FP}(1)$ & 1.9431 & 0.4697 & 4.14 & 1.02 & 2.86 \\
\hline $\mathrm{DU}(1)^{\star} \mathrm{WE}(1)$ & -1.3891 & 0.2756 & -5.04 & -1.93 & -0.85 \\
\hline $\mathrm{DU}(2)^{\star} \mathrm{WE}(1)$ & -1.0553 & 0.3212 & -3.29 & -1.68 & -0.43 \\
\hline
\end{tabular}

In Table-4 estimated conditional $\mathrm{D}(1)^{*} \mathrm{DU}(1)$ odds ratio indicated that desire for more children is bout 31 times more likely to occur for the couples whose duration of marriage is 0-9 years as compare to those whose duration of marriage was 20 or more years. Conditional $\mathrm{D}(1)^{\star} \mathrm{FP}(1)$ odds ratio gave that desire for more children is just $5 \%$ likely to occur for those husband who have approved family planning as compare to those who have disapproved the family planning. Similarly estimates of parameters $\mathrm{DU}(1)^{\star} \mathrm{FP}(1)$ and $\mathrm{DU}(2)^{\star} \mathrm{FP}(1)$ gave that approval of family planning is less likely to occur for those couples whose duration of marriage was 20years or mire than those whose duration of marriage was $0-9$ years. Approval of family planning is $1 / 6.89=0.14$ i.e. $14 \%$ likely to occur for those couples whose duration of marriage was 10-19 years, at each combination of levels of other factors.

\section{Group 4:}

Four factors which are FP, h, P and PV were included in the group-4. Backward elimination procedure gave the model with generating class $\left(P, F P^{*} P V, H^{*} P V\right)$ with $G^{2}=34.905$, d.f. $=26, p=0.114$. Due to absence of $F P^{*} H, F P^{*} P, H^{*} P$ and $P \star P V$, the fitted model has conditional independence structure as given Estimates of parameters for model in group 4 given table- 5 
Farooq Ahmad, Sohail Chand

Table 5:

\begin{tabular}{|l|c|c|c|c|c|}
\hline \multirow{2}{*}{ Parameters } & \multirow{2}{*}{ Estimates } & \multirow{2}{*}{$\mathrm{S}$ E } & \multirow{2}{*}{ Z-value } & \multicolumn{2}{|c|}{$\begin{array}{c}\text { Asymptotic 95\% } \\
\text { Confidence Interval }\end{array}$} \\
\cline { 4 - 6 } & & & & Lower & Upper \\
\hline Constant & 1.6915 & - & - & - & - \\
\hline $\mathrm{FP}(1)$ & -0.4829 & 0.1363 & -3.54 & -0.75 & -0.22 \\
\hline $\mathrm{H}(1)$ & 1.4992 & 0.2306 & 6.50 & 1.05 & 1.95 \\
\hline $\mathrm{H}(2)$ & 1.4895 & 0.2308 & 6.45 & 1.04 & 1.94 \\
\hline $\mathrm{P}(1)$ & -0.3591 & 0.1448 & -2.48 & -0.64 & -0.08 \\
\hline $\mathrm{P}(2)$ & -0.0808 & 0.1340 & -0.60 & -0.34 & 0.18 \\
\hline $\mathrm{PV}(1)$ & -0.8764 & 0.3647 & -2.40 & -1.59 & -0.16 \\
\hline $\mathrm{FP}(1)^{\star} \mathrm{PV}(1)$ & 0.9103 & 0.2714 & 3.35 & 0.38 & 1.44 \\
\hline $\mathrm{H}(1)^{\star} \mathrm{PV}(1)$ & -1.3741 & 0.4227 & -3.25 & -2.20 & -0.55 \\
\hline $\mathrm{H}(2)^{*} \mathrm{PV}(1)$ & -0.4133 & 0.3777 & -1.09 & -1.15 & 0.33 \\
\hline
\end{tabular}

Estimate of parameter $\mathrm{FP}(1)^{\star} \mathrm{PV}(1)$ in the form of conditional odds ratio indicated that approval of family planning methods is occurring 2.485 times more to those husbands whose political view is democratic rather than Islamic, controlling the $\mathrm{H}$ and $P$. This gives the strong positive association between approval of family planning and liberal democratic political view.

\section{Logit model:}

The factors associated with variable under study FP in the four groups were taken to develop the logit model in order to find the dependence of the factors associated with FP and their combined effect on the probability of adopting the contraceptives. HW, N, D, DU and PV were taken in logit model. If $\Pi$ is the probability for the approval of family planning methods, the logit model has form the importance of fitting the logit model is that it can analyze the dispersion in the dependent variable. Total dispersion of the binary dependent variable FP has been divided into dispersion explained by the model and residual dispersion (unexplained).

Table 6: $\quad$ Analysis of Dispersion

\begin{tabular}{|l|c|c|c|}
\hline Source of Dispersion & Entropy & Concentration & d. f. \\
\hline Due to Model & 79.0124 & 65.6277 & 8 \\
\hline Due to Model & 129.3231 & 83.9973 & 295 \\
\hline Total & 208.3355 & 149.6250 & 303 \\
\hline
\end{tabular}


From the analysis of dispersion in Table-6, we can calculate statistic similar to $\mathrm{R}^{2}$ in regression analysis. The ratio explained by the model using entropy criterion was found to be $37.93 \%$.

In order to see the combined effect of factor PV, N, D, DU and HW on FP, we have found the odds of acceptance of family planning.

Table 7:

\begin{tabular}{|l|c|c|}
\hline Explanatory Factors with Levels & Logit & $P(F P=1) / P(F P=2)$ \\
\hline$D(1), P V(1), H W(1), N(1), D U(1)$ & 2.2022 & $\mathrm{e}^{2.2022}=9.044$ \\
\hline $\mathrm{D}(1), \mathrm{PV}(1), \mathrm{HW}(1), \mathrm{N}(1), \mathrm{DU}(2)$ & -0.899 & $\mathrm{e}^{-0.899}=0.4064$ \\
\hline $\mathrm{D}(1), \mathrm{PV}(1), \mathrm{HW}(1), \mathrm{N}(2), \mathrm{DU}(1)$ & 1.4836 & $\mathrm{e}^{1.4836}=4.4085$ \\
\hline $\mathrm{D}(1), \mathrm{PV}(1), \mathrm{HW}(1), \mathrm{N}(2), \mathrm{DU}(2)$ & 0.2006 & $\mathrm{e}^{0.2006}=1.2201$ \\
\hline
\end{tabular}

Note:- $\mathrm{D}(2), \mathrm{PV}(2), \mathrm{HW}(2), \mathrm{N}(3), \mathrm{DU}(3)$ are reference categories of these factors. Estimates of these levels as set to zero.

We can see in serial no. 2 of table 7 the probability of approving the family planning is $41 \%$ less than probability of disapproving the contraceptives, with the combined effect of given levels of factors PV, N, D and HW in order to investigate that which are factors upon which the variable FP is highly depending, we have found measure of association using entropy and concentration criteria by dropping each factor one by one and watch the effect of dropping this factor upon dispersion explained by logit model. Table 8 shows the detail of this procedure

Table 8:

\begin{tabular}{|l|c|c|l|}
\hline Dropping Factors & Entropy & Entropy Change & \% Change \\
\hline D & 0.2150 & $0.3793-0.2150=0.6143$ & $16.43 \%$ \\
\hline HW & 0.2862 & $0.3793-0.2862=0.0931$ & $9.31 \%$ \\
\hline N & 0.3265 & $0.3793-0.3265=0.0528$ & $5.28 \%$ \\
\hline DU & 0.3251 & $0.3793-0.3251=0.0542$ & $5.42 \%$ \\
\hline PV & 0.3608 & $0.3793-0.3608=0.0185$ & $1.85 \%$ \\
\hline
\end{tabular}

Note: 0.3793 is the ration explained by logit model

On basis of table 8 we may make the groups of explanatory variables upon which FP is highly depending, moderately depending and slightly depending. So D and $\mathrm{HW}$ are the factors upon which FP is highly depending 


\section{Conclusion}

It has been found that husband-wife discussion upon the size of family is the most important factor, highly influencing upon the decision making of acceptance of family planning. The factor education attainment of husband was found to be highly associated with variable husband wife discussion so it has been found that by increasing the educational level of husband, acceptance of family planning can be increased. Moreover, we can conclude that like other family matters, the decision upon family size is highly influenced by males' opinion. The factor, no. of living children for $N(1)$ i.e. $0-1$ child has negative effect upon acceptance of family planning while the factor N(2) i.e. no. of children $2 \&$ above has positive effect upon the practice of family planning. Those husbands who have democratic political view, which was considered a more liberal view according to context of research, have 2.48 times more chance to adopt the family planning methods as compared to those who have Islamic political view, which were more orthodox. Thus approval of contraceptives was more likely to occur for those couples whose religious view was low as compared to those who want strict Islamic political system. Senior couples were less likely to believe on contraceptives as compared to those couples whose duration of marriage was less than 20 years, this factor may be significant due to the fact that senior couples think that their family is now complete and they do not need more children.

\section{Acknowledgements}

The authors would like to thank to an anonymous referee for helpful comments leading to a significantly improved article.

\section{References}

1. Afifi A. A. and Clark, V., (1994), Computer aided multivariate analysis, 3rd edition. Chapman and Hall, London.

2. Agresti A., (1996), An introduction to categorical data analysis, John Wiley and Sons, New York.

3. Ahmad, F., (2001), Unpublished M.Phil Thesis.

4. Ali, S, and White, F.M., (2005), Family planning practices among currently Married women in Khairpur district, Sindh, Pakistan, Journal of College of Physicians and Surgeons of Pakistan, Vol. 15 No. 7, 422-425.

5. Farooqi, M. and Naseem Iqbal, (1994), Interpersonal Communication in Family Planning in Pakistan, Pakistan Development Review Vol.33 No.4, 677-684.

6. Hakeem, A., (1995), Desire for no more children and contraceptive use in Pakistan, Pakistan development review Vol. 34 No. 4, 563-578.

7. Mehmood, N. and Ali, M., (1997), Pakistan Population Planning in Pakistan issue in implementation and its impact, Pakistan Development Review Vol. 36 No. 4, 875-888.

8. Sabihuddin, M. and Jamal, H., (1993), Determents of marital fertility in Pakistan: and application of the synthes is framework, Pakistan development review Vol. 32 No. 2, 199-220.

9. Zafar, M.I., (1996), Husband Wife role as co-relate of contraceptive and fertility behavior, Pakistan development review Vol. 35 No. 2, 145-170. 